\title{
Efficacy of Environmental Health E-Training for Journalists
}

\author{
Megan L. Parin ${ }^{1}$, Elissa Yancey ${ }^{2}$, Caroline Beidler ${ }^{3}$, \& Erin N. Haynes ${ }^{1}$ \\ ${ }^{1}$ College of Medicine, University of Cincinnati, Cincinnati, Ohio, USA \\ ${ }^{2}$ McMicken College of Arts \& Sciences, University of Cincinnati, Cincinnati, Ohio, USA \\ ${ }^{3}$ Neigbors for Clean Air, Marietta, Ohio, USA \\ Correspondence: Megan L.Parin, College of Medicine, University of Cincinnati, Cincinnati, Ohio, USA
}

\author{
Received: April 15, 2014 Accepted: April 29, 2014 Available online: May 15, 2014 \\ doi:10.11114/smc.v2i1.387 URL: http://dx.doi.org/10.11114/smc.v2i1.387
}

\begin{abstract}
Communities report a low level of trust in environmental health media coverage. In order to support risk communication objectives, the goals of the research study were to identify whether or not there is a gap in environmental reporting training for journalists, to outline journalists' methods for gathering environmental health news, to observe journalists' attitudes toward environmental health training and communication, and to determine if electronic training (online/e-training) can effectively train journalists in environmental health topics.

The results indicated that environmental journalists have very little to no formal environmental journalism training. In addition, a significant percentage of journalists do not have any formal journalism education. Respondents most preferred to receive continuing environmental journalism training online. Online instruction was also perceived as effective in increasing knowledge and providing necessary reporting tools, even among participants adverse to online instructional methods.

Our findings highlight the changing media climate's need for an increase in electronic journalism education opportunities to support environmental health journalism competencies among working professional journalists.
\end{abstract}

Keywords: environmental reporting training, media-scientist communication, environmental health reporting, reporting science, journalist training, online training, journalism continuing education

\section{Introduction}

Media outlets are potentially invaluable community partners for researchers using a community-based participatory research (CBPR) approach. CBPR is a scientific research method that engages with the study site's community to enhance research outcomes (Israel, Schulz, Parker, Becker, 2001; Minkler and Wallerstein, 2003; O'Fallon and Dearry, 2002); however, reported disparities in community members' information-seeking behavior and lack of trust in the news media leave reporters underutilized and/or ineffective in achieving CBPR risk communication objectives. We hypothesize that a gap in environmental health-trained journalists is partly responsible for disconnect between community members and media outlets, and that collaboratively developed scientist-journalist e-training modules would improve risk communication to underserved populations.

For our purposes, media outlets are classified as a subset of the community since they are key facilitators of risk communication. The Communities Actively Researching Exposures Study (CARES) is a CBPR-structuredscientific research study investigating the impact of air pollution on children's neurodevelopment in eastern Ohio (Haynes et al., 2011). One goal of CARES research is to use innovative communication strategies between academic researchers and key community liasons (community members, media outlets, and local academics) to maximize the reach of study findings and engage community members in the research process. For this analysis, we evaluated the potential of scientist-lead online education modules for providing quality interface between media outlets and academics to achieve CBPR risk communication aims.

\subsection{The Journalist-Scientist Relationship}

The need for reform in journalism education (j-education) and training is becoming increasingly important in the digital age, and the goals of j-education innovation closely align with those of CBPR. The development of synergistic training opportunities between these two camps, media professionals and scientists, can produce mutually beneficial, 
interdisciplinary relationships. Journalists are gatekeepers of information valuable in disseminating public health information, especially to underserved communities in which media outlets struggle to provide thorough news coverage (Poynter, 2013; George, 2009). To maximize the community benefits of risk communication, researchers, viewed as highly trustworthy in our prior community research, need to ensure their results are reported with integrity and accuracy by journalists (Haynes et. al., 2011). Research conducted by the Society of Environmental Journalists(SEJ) suggests professional relationships between scientists and journalists can increase public understanding of science and health issues (Valenti, 2005). Researcher-developed online training for journalists could achieve these aims while enforcing the Nieman Lab's recommendation for a push toward the hospital model of journalism education and training, which encourages innovations in digital tools and techniques, collaborative approaches, and a movement toward not only informing, but engaging with communities (Poynter, 2013). As a community's environmental health concerns grow, so do the responsibilities of researchers and media outlets to directly provide risk communication reflecting the community's unique environmental health profile. Here arises the need for optimally-trained journalists to deliver essential, accurate, and timely information.

\subsection{The State of Journalism Education}

To complicate risk communication, the professionalism of journalism is at stake with outmoded curricula failing to incorporate the public's online news-seeking behaviors and mobile technologies putting journalism degrees at risk for irrelevancy. In addition to the overall lack of modernized journalism degree programs, to date, the SEJ's Directory of Science and Environmental Communication Programs, indicates an abysmally small number of science journalism degree programs (19), certificate programs (4), tracks and concentrations (17), and courses taught (21) at the undergraduate and graduate level With forecasts estimating 50\% of all universities will be bankrupt within the next 15 years (Melton, 2014), stagnant journalism degree programs are easy targets for budget-strapped universities.

With academic training opportunities waning, it is necessary to examine if alternate training sources can uphold industry standards traditionally reinforced in formal degree programs. MOOCs (Massive Open Online Courses) are free, online courses that could potentially house media training modules, but at the time of publication, there has only been one MOOC developed to address community journalism. In April 2014, UK-based Cardiff University to create the world's first Community Journalism MOOC (Cardiff 2014). Lead by Professor Richard Sambrook, Director of the Centre for Journalism and former Director of Global News at the BBC, the Community Journalism MOOC is designed to provide "hyperlocal" journalists with the tools they need to infuse their community with new technology (Cardiff 2014). MOOCs like these are typically offered through companies like Coursera and edX, which take the place of in-house university faculty. However, they also fail to offer academic credit, leaving them vulnerable to criticism regarding their professionalism (Melton 2014). Related to MOOCs, Third-Party Online Courses (T-POC) offer the same content and expert leadership, with the the OC (online course) company partnering with the university to limit enrollment to students paying tuition to have the course count towards a degree (Melton 2014).

While the sustainability of both MOOCs and T-POCs remain questionable, with some academic leaders saying they are over hyped and will inevitably crash (Melton 2014), traditional community journalism training methods, like the Institute for Journalism \& Natural Resources (IJNR) conduct in-field training to increase community journalism competencies in relevant sciences, industries, and cooperation with community members (Institute 2014). Much like university degree programs, these methods use selection criteria to screen for quality candidates,but are limited in their ability to reach all qualified journalists.

Adding fuel to the fire, in the professional sphere the bulk of revenue has shifted from print to online sources, resulting in layoffs and budget cuts at many media outlets, leaving experienced, expert reporters, including science and health journalists, out of work. Yet, while there are fewer and fewer positions for qualified reporters, there are more and more environmental issues to cover (George, 2009). This creates an environment in need of supplemental education and training to fill the void (Poytner, 2013).

In the wake of the reshaping of media companies, resources for journalists remain limited, but e-learning could supplement traditional education as an economically viable, industry-relevant training alternative for current and future media professionals (Poynter, 2013; Pew, 2013). Increased online training could help maintain industry professionalism and integrity in a new era of reporting (Poynter, 2013). Currently, Poynter's NewsUniversity, an open-access, online training site, serves more than 300,000 users, including journalists, bloggers, freelance writers and journalism students (NewsUniversity, 2014). NewsUniversity offers beat-specific courses, seminars, webinars and other training and education opportunities, many of which are free, though some are fee-based (NewsUniversity, 2014). Their Specialized Reporting Institutes, offered in conjunction with non-profit organizations including the SEJ and the Robert R. McCormick Foundation, have addressed specific environmental reporting topics, including the Gulf Oil Spill and Shale Gas and Oil Development. A boom in online journalism training programs continues, with more than 55 million Google 
search results for "online journalism training" (Google, 2014), though their quality and levels of participation and impact have yet to be studied. While some, like NewsUniversity, are affiliated with professional journalism organizations with long histories; others, like MulinBlog: A digital journalism blog, have no such connections, but reported 20,000 page views in April 2014 alone (MulinBlog, 2014). At the same time, scholarly reviews of journalism education in general are scarce, with reviews of online options even scarcer.

From an environmental health perspective, journalists' training levels indicate the need for more online training, and CBPR researchers need more channels for community engagement. Pairing the two into a synergistic online learning community could advance the goals of both. Although there is a clear need to innovate alternative training opportunities for journalists and increase collaboration with CBPR researchers, we could find no research conducted about the efficacy of expedited, topic-specific online e-training for journalists.

\subsection{Research Aims}

The study was designed to evaluate how online media training in air pollution and health can improve risk communication, thus augmenting CBPR aims and advancing opportunities in the new wave of continuing education in journalism. Specifically, the study focused on observing journalists' attitudes toward training and to determine if there is a gap in environmental health training for journalists that might impact the completeness of information delivered to at-risk populations.

\subsection{Research Hypotheses}

Following the above literature review, three hypotheses were generated:

1) Environmental health training will be limited among professional journalists who also have an absence of online training histories.

2) Online training will be the preferred training mechanism among journalists and greater positive attitudes about environmental health reporting will be affected among online-preferring journalists than non-online-preferring journalists.

3) Scientist-led journalist training will increase reporting competencies.

\section{Method}

\subsection{Participant (Subject) Characteristics}

Thirty-four media professionals participated in the research (table 1). Eligible participants were defined as any professional journalist actively publishing in the media. No demographic restrictions were put in place. No media channels were excluded.

\subsection{Research Design}

An e-learning module was collaboratively developed by CARES academic researchers, academic media specialists (AMS), and community media partners (CMP). Participants were emailed a link to participate in the module. Online administration was selected to quickly reach widespread participants and to allow for asynchronous completion. The phases followed the human response to communications model-exposure to a stimulus, the comprehension of the stimulus, and the response to the stimulus (Belch, 2011).

In the first phase, subjects asynchronously completed a thirty-minute environmental health e-learning module titled "Air Particles and Health". The module topic was selected based on prior findings in which CARES community members ranked air quality as the most concerning local environmental threat (Haynes et. al., 2011). After the topic was identified, together, the academic and community partners designed the training module based on a four-point learning method:

1) Introduce: Outline objectives

2) Define: Discuss each objective

3) Review: Summarize key points

4) Reinforce: Provide additional resources

Under the assumption participants would not have a basic understanding of air quality; four learning objectives were identified to align with the following news gathering and production journalism competencies: data analysis and synthesis, source development, advanced online information search, and understanding audience needs. All objectives were designed to meet journalism competencies in understanding information adequately enough to write a news story aimed at addressing the CARES community's concerns:

1a. What is particulate matter and where does it come from? 
1b. Who is most susceptible to particulate matter and why?

1c. What are some of the health effects associated with particulate matter?

1d. Where can you get additional information about particulate matter?

The module featured a video lecture presented by subject-matter expert Patrick Ryan, PhD, alongside summary slides and relevant illustrations (figure 1). Subjects were able to pause, rewind, and advance the module, but were required to answer quiz questions intermittently before advancing to the next lecture topic. After completing the module, participants were given access to lecture notes to download and keep for future reference.

In the second phase, participants answered survey questions about the module evaluating 1. the adequacy of the module, 2. environmental health reporting training and experience, and 3. demographics. The survey was developed by CARES AMS and reviewed by CARES CMP and CARES community partners (CP). For module-related questions, respondents were asked to rate their answers on a five-point Likert Scale (1-Strongly disagree, 5-Strongly agree). An additional seventeen demographic items were included (gender, age, ethnicity, race, etc.), including items related to journalism and non-journalism education, journalism training, environmental journalism reporting history, and environmental journalism news gathering procedures.

Like other research, we hypothesized successful completion of the online module would broaden participants' knowledge about the topic, thus improving their ability to share information, glean insights through reporting, and determine if any relevant connections should be reported to the community (Becker, 2004).

After successfully completing the e-learning module, a CARES CMP published an article on air quality in the community newspaper. More research is necessary to determine how, if at all, knowing the journalist was trained by a research scientist impacts the community's trust in the media.

\subsection{Sampling Procedures}

Subjects were recruited from July 2010-September 2010. Recruitment channels were selected based on the recommendations of CARES CMP and AMS. Participants were primarily recruited from an SEJ member listserv. SEJ members were specifically targeted since it is the only North-American association of professional journalists dedicated to promoting better coverage of environmental issues, specifically those affecting underserved communities (Society of Environmental Journalists [SEJ], 2013). It was therefore assumed that SEJ members would be the best barometer for evaluating the current state of environmental health journalism training. Secondarily, participants were recruited using professional media contacts provided be CARES AMS and CMP.

\subsection{Research Procedure}

Participation was voluntary and respondents were informed their responses would be kept confidential and their identities anonymous. Prior to participation, participants were told by clicking "submit" at the end of the survey, they consented to participate in the research. Participants were informed they could withdraw from the study at any time. Research study invitations were emailed to members of the Society of Environmental Journalists, to CARES AMS contacts, and to CARES CMP contacts.

\section{Results}

The two-phase e-learning module was conducted with 34 professional journalists from July 2010-September 2010 . Respondents were highly educated, with the majority (61\%) holding a Master's degree or higher (table 2). As expected, a majority of respondents $(82 \%)$ reported membership in the SEJ (table 1). Despite overwhelming representation of professional society membership, $41 \%$ of respondents reported receiving no type of formal journalism training, while a notable percentage of respondents, also $41 \%$, indicated a non-journalism or communications discipline as their former field of study (table 2). There was an even wider gap in environmental journalism training among participants, with only $26 \%$ of respondents indicating prior training in environmental journalism (table 2). To follow-up, we asked respondents to describe their formal training in reporting environmental health effects. Of the respondents who said they received training in environmental health reporting, nearly all classified this training as classroom-based, with college-level environmental reporting classes being the most common response $(66 \%, \mathrm{n}=6)$ (table 2). Other responses included training at professional conferences and seminars or practical professional experiences like internships, mentorships, and fellowships. Zero participants indicated receiving training from an environmental health researcher. This is consistent with existing research that reports upwards of $83 \%$ of journalists are not trained in health reporting, and less than 50\% have environmental health training (Becker, 2004; Voss, 2002). It is noteworthy that, considering today's need, little progress has been made in the past decade to increase environmental and health-related j-training.

\subsection{Environmental Reporting Activity}

Although lacking in environmental journalism training, $41 \%$ of respondents indicated reporting an environmental health 
story within the three months leading up to the training module (table 2). Of the $41 \%$ reporting on environmental health, $35 \%$ of respondents indicated writing four or more environmental health stories within the same time period.

When asked to identify primary and secondary information sources used in environmental health reporting, only $36 \%$ of respondents reported using a University researcher as their primary source, and even fewer, 27\%, said they used researchers as a secondary source. A majority of participants, 57\%, said they did not directly contact a researcher when reporting recent environmental health stories. There was a noticeable lack of community perspectives included in the reporting process, with only $14 \%$ of respondents indicating using local residents as a primary reporting source and $10 \%$ consulting with locals as a secondary source.

\subsection{Module Effectiveness}

All respondents reported that the module was effective in improving knowledge, providing essential reporting tools, and piquing interest in writing a news story about the module topic (table 3). The majority of participants (62\%) reported an "Average" level of knowledge about air particles and health prior to taking the module. After taking the module, $88 \%$ of respondents said they agreed or strongly agreed that their knowledge about air particles and health was improved (table 3). Similarly, $76 \%$ of respondents said the module gave them the tools needed to write an effective news story about air particles and health. However, only a slight majority, 53\%, said the module made them interested in writing a news story about air particles and health (table 3). More research is needed to determine if there is a relationship between the module topic and its relevance to reporting area in piquing interest.

Although "online module" was the most preferred method of instruction among all respondents (53\%) (table 4), the $47 \%(n=13)$ of respondents who indicated a preference for non-online, traditional training, like brochures, reported finding the online training module to be effective (table 3 ). The majority of this sample $(81 \%, n=13)$ "Agreed" or "Strongly Agreed" that the online module was effective in improving their knowledge about air particles and health, while post-survey results show $75 \%$ of this respondent sample also "Agreed" or "Strongly Agreed" that the online module was adequate in providing the tools necessary to write a news story covering the module topic (table 3 ). Half of these respondents (50\%) agreed that the module piqued their interest in writing a story about the module topic. This was consistent with the online-preferring sample, in which $56 \%$ of respondents indicated that the module made them interested in writing about the module topic (table 3). However, it is prudent to note that a comparison among the two groups, online preferring and non-online preferring, shows those who prefer non-online training are slightly more dissatisfied with the module than those who prefer online training. When asked, "After taking this module, are you more interested in writing about environmental health topics?," $50 \%$ of online-preferring respondents answered, "Yes," while just 38\% of non-online-preferring respondents answered "Yes". When asked if the module gave them the tools necessary to write about the module topic, $75 \%$ of non-online sample said they "Agreed" or "Strongly agreed," just below the $83 \%$ of the online-preferring respondents who reported that the module gave them the necessary tools to write about the topic. Similarly, while $94 \%$ of the online respondent group said they felt the online module increased their knowledge about air particles and health, $81 \%$ of non-online respondents said they felt the module improved their knowledge (table 3).

After successfully completing the e-learning module, a CARES CMP published an article on air quality in the community newspaper. More research is necessary to determine if reported community trust in a media item is affected by knowing the journalist was trained by a research scientist.

\subsection{Summary of Results}

Findings show despite environmental reporting activity, there is a lack of environmental training, virtually no direct contact with scientists during news gathering, and an absence of community representation (consideration) in environmental health coverage.

As expected, there is a lack of environmental health training among journalists reporting on environmental issues. Further, there is a complete absence of online environmental training experiences, and a surprisingly low number of journalists trained in journalism or communications.

As hypothesized, online training was the preferred method of instruction among journalists. Notably, after online training, journalists indicating a preference for non-electronic training had more positive outcomes regarding the module's effectiveness than journalists preferring online.

Also consistent with our initial hypothesis, the vast majority of respondents reported that the online training module increased their knowledge about air particles and health and provided them with enough information to write about the topic. A smaller percentage, about 50\%, reported that training piqued their interest in writing a news story related to the module topic. More research is needed to determine how to increase interest in reporting on specific environmental health topics. 


\section{Discussion}

\subsection{Future Directions}

Our study indicated that journalists are undertrained in environmental health reporting. We also found an overall lack of basic journalism training. Considering the degeneration of environmental journalism positions, it was not surprising that journalists lacked environmental journalism training, but a complete absence of online training histories confirms that journalists are, on the whole, not receiving modernized training to keep pace with advances in the field. While organizations like NewsUniversity currently serve more than 300,000 constituents and offer a growing number of specialized online learning modules for no to nominal costs, few of the journalists in this study had participated in online learning. In order to maintain journalistic standards and further the mission of CBPR, it is evident that more journalists need to be recruited to beat-specific continuing education opportunities. Future research could also benefit from an examination of journalists on the whole, rather than research specific to SEJ members, for a more accurate industry cross-section.

Our survey also indicated a strong preference for online training among journalists, and post-test findings show online training is thought to be equally effective among both online and non-online preferring journalists.

Considering that online training is both a time- and cost-effective solution to address the problem of inadequate training opportunities for journalists, online training opportunities should be increased. Studying the impact of online learning modules at NewsUniversity, in addition to measuring the impact of CBPR-specific training modules, is needed to begin to build a body of evidence of what constitutes effective online training for journalists and how online modules can impact reporting practices. Further, adding another measure evaluating the quality of participants' pre- and post-module writing samples could corroborate the efficacy of module-based training.

Yet, findings indicate an overall lack of interest in the training topic, emphasizing the importance of finding ways to not only effectively train, but engage journalists in environmental health e-training. If training modules fail to generate interest and personal investment in the subject, it is unlikely that journalists will propose stories and fight for increases in environmental health media coverage, resulting in limited public exposure to a relevant environmental health issues. There is also the additional benefit of applying the same methods used to increase interest among journalists to enhance community engagement and subject matter comprehension.

Research confirmed that scientist-led journalist training, in part, fulfills reporting competencies related to news information and gathering. This supports the need for more interdisciplinary partnerships between scientists, media insiders, and communications academics to develop online training modules that will specifically address voids in journalism training. Effective administration systems also need to be developed to connect professional journalists to online continuing education modules.

Our survey results also indicated that journalists do not, in general, consult with community members when reporting on local environmental issues. More interaction between local media and community members should be encouraged to develop new methods of community engagement, especially in the online realm, which would both further the media's mission to establish a well-informed electorate as well as support CBPR risk communication objectives to ensure public engagement and understanding in scientific research.

Of particular interest in our results was reportedly high levels of education and general journalism training among rural journalists.. The absence of environmental journalism training despite high education levels could suggest limited access to environmental journalism training, limited awareness of environmental journalism training, limited interest in environmental journalism training, or even a possible bias in environmental journalism training toward urban journalists and current SEJ members, which should be addressed.

\subsection{Limitations}

More research is needed to determine if the void in environmental and basic journalism training can be attributed to a lack of training opportunities and/or to a lack of professional resources in today's budget-strapped media. This also calls for a broader investigation of how, if at all, the lack of training impacts the quality and effectiveness of environmental health communications delivered to environmentally-affected populations to see if increased online training improves community engagement and understanding. Although participants, including a CARES CMP (partnership discussed in prior research publications), published articles on air quality after participating in the research, we did not evaluate participants' pre- and post-module reporting samples. These samples could potentially be analyzed to better determine the efficacy of the module.

Further, prior research showed community members do not trust the news media, but greatly trust university researchers. An evaluation of the community's receptivity to journalists' post-module articles could elucidate whether or not direct scientist-journalist training impacts trust levels, which could support the need for more interdisciplinary relationships in 
training to affect better journalism and CBPR outcomes. To complement this research, and our findings that journalists do not generally consult with community members when reporting on environmental health issues, research should be conducted to determine if there is link between the amount of interaction between journalists and community members and the amount of trust the community has in news media. Further exploration of this relationship could benefit the media and CBPR fields, especially in determining the most effective avenue for information dissemination: through media outlets, professional organizations, or other avenues. It is also suggested that research be conducted to identify specific obstacles in increasing journalism training to better inform the future direction of journalism education.

Relatedly, considering the overall lack of community consultation in the reporting process, there seems to be a need for more research into how well journalists understand reader needs and how well readers are able to accurately interpret and understand the information being reported. This is especially important in this transitional period in journalism education, where it is necessary to monitor if journalists are adequately prepared to uphold the most basic professional journalistic standards.

Although the research showed both online and non-online preferring journalists found online training equally effective, we did not confirm whether or not journalists indicating a preference for online training reported higher satisfaction with the online training modules. This suggests that online training could be a highly effective means of training regardless of training type preference; however, we did not establish if it is a reliable indicator of willingness to participate in online training. To encourage participation and eliminate barriers to participating in online training among all journalists, regardless of preferred training type, it would be helpful to determine if journalists preferring non-online training have a negative attitude toward online training.

On a similar note, our research did not explore reasons contributing to the journalists' lack of interest in the training topic (air particles and health). Further exploration into how variables like module design, relevance of topic to the journalist's coverage area, lack of sensationalism, current reporting assignments and responsibilities, and local socio-political issues, to name a few, could impact journalists' level of interest in the topic and willingness to report on the topic is needed. Further investigation into how the trend of environmental news desk closures could affect low interest levels in reporting on environmental health topics and the number of environmental health stories being reported should be jointly conducted.

It is also recommended that more research be conducted to determine how geographic delineation moderates the demand for, opportunities for, and need for continued training and education, especially in an online domain, which provides a platform to deliver world class education to even the most remote corners of the nation, ensuring underserved populations are equally benefitting from investments in journalist training.

\section{Figures and Tables}

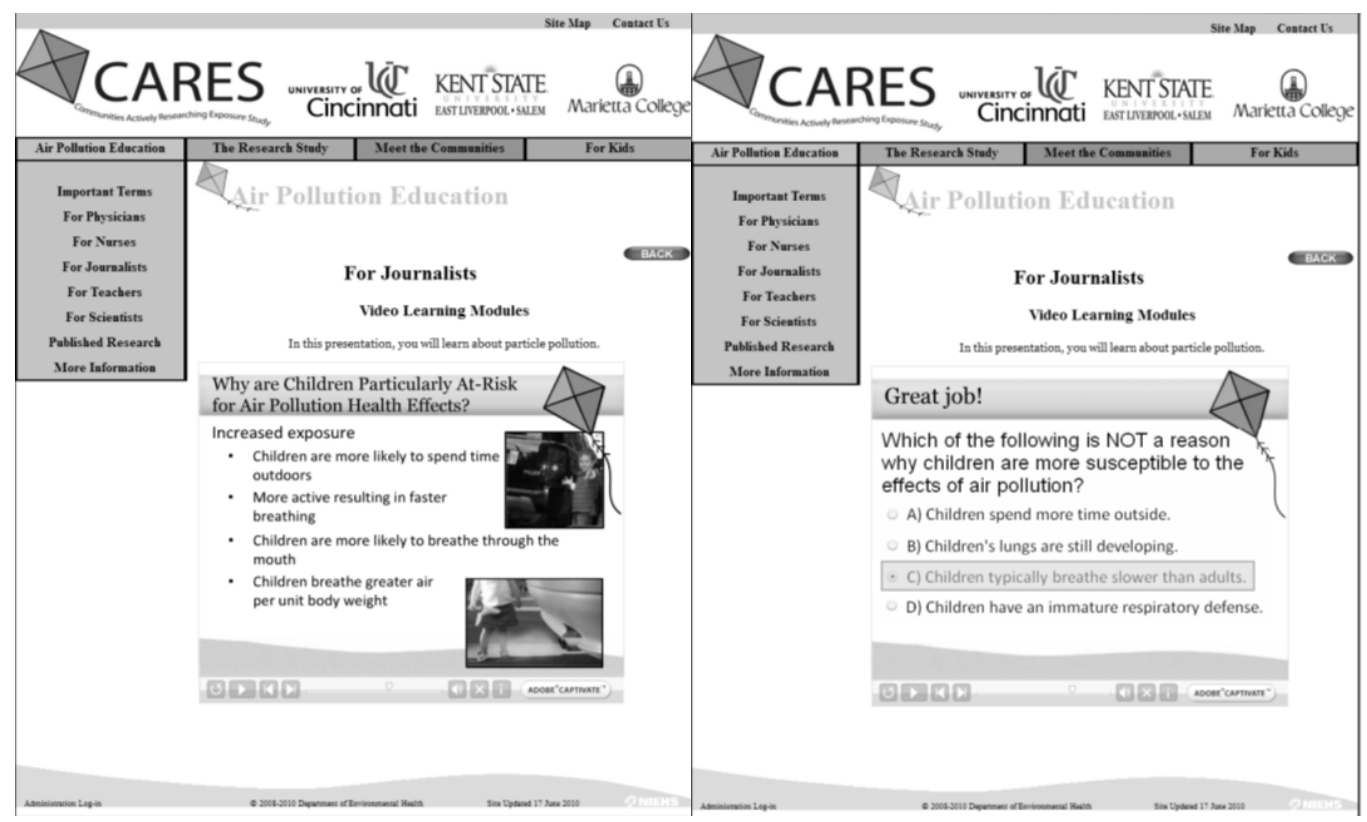

Figure 1. Screenshots of online training module

Description: Summary slides accompanied by audio use plain language to communicate community-relevant information 
to journalists (left). Intermittent quiz questions serve as knowledge checks to keep journalists engaged (right).

Table 1. Characteristics of the Journalist Survey participants by training method preference

\begin{tabular}{|c|c|c|c|}
\hline & All $(n=34)$ & Prefers Online $(\mathrm{n}=18)$ & $\begin{array}{c}\text { Prefers } \\
\text { Other }(n=16)\end{array}$ \\
\hline Variables & $\mathrm{n}(\%)$ & $\mathrm{n}(\%)$ & $\mathrm{n}(\%)$ \\
\hline \multicolumn{4}{|l|}{ Gender } \\
\hline Male & $11(32 \%)$ & $6(33 \%)$ & $5(31 \%)$ \\
\hline Female & $23(67 \%)$ & $12(67 \%)$ & $11(68 \%)$ \\
\hline \multicolumn{4}{|l|}{ Age } \\
\hline $20-30$ & $13(38 \%)$ & $9(50 \%)$ & $4(25 \%)$ \\
\hline $31-40$ & $3(9 \%)$ & $2(11 \%)$ & $1(6 \%)$ \\
\hline $41-50$ & $8(24 \%)$ & $3(17 \%)$ & $5(31 \%)$ \\
\hline $50+$ & $5(15 \%)$ & $4(22 \%)$ & $6(38 \%)$ \\
\hline \multicolumn{4}{|l|}{ Ethnicity } \\
\hline Hispanic/Latino & $3(9 \%)$ & $2(11 \%)$ & $0(0 \%)$ \\
\hline Non-Hispanic/Latino & $31(91 \%)$ & $16(89 \%)$ & $16(100 \%)$ \\
\hline \multicolumn{4}{|l|}{ Race } \\
\hline Caucasian & $30(88 \%)$ & $16(89 \%)$ & $14(88 \%)$ \\
\hline Non-Caucasian & $4(12 \%)$ & $2(11 \%)$ & $2(13 \%)$ \\
\hline \multicolumn{4}{|l|}{ SEJ Member } \\
\hline No & $6(18 \%)$ & $3(17 \%)$ & $3(19 \%)$ \\
\hline Yes & $28(82 \%)$ & $15(83 \%)$ & $13(81 \%)$ \\
\hline
\end{tabular}

Description: Self-reported respondent demographics.

Table 2. Education, training, and professional experience of the Journalist Survey participants by preferred training method

\begin{tabular}{|c|c|c|c|}
\hline & All $(n=34)$ & Prefers Online $(\mathrm{n}=18)$ & $\begin{array}{c}\text { Prefers } \\
\text { Other }(n=16)\end{array}$ \\
\hline Variables & $\mathrm{n}(\%)$ & $\mathrm{n}(\%)$ & $\mathrm{n}(\%)$ \\
\hline \multicolumn{4}{|l|}{ Highest degree } \\
\hline $\begin{array}{l}\text { HS diploma/ } \\
\text { Associate's degree }\end{array}$ & $1(3 \%)$ & $1(6 \%)$ & $0(0 \%)$ \\
\hline Bachelor's degree & $12(35 \%)$ & $7(39 \%)$ & $5(31 \%)$ \\
\hline Master's degree & $19(56 \%)$ & $10(56 \%)$ & $9(56 \%)$ \\
\hline Doctoral degree & $2(6 \%)$ & $0(0 \%)$ & $2(13 \%)$ \\
\hline \multicolumn{4}{|l|}{ Field of study } \\
\hline $\begin{array}{l}\text { Journalism/ } \\
\text { Communications }\end{array}$ & $20(59 \%)$ & $12(67 \%)$ & $8(50 \%)$ \\
\hline $\begin{array}{l}\text { Non-Journalism/ } \\
\text { Communications }\end{array}$ & $14(41 \%)$ & $6(33 \%)$ & $8(50 \%)$ \\
\hline \multicolumn{4}{|l|}{ Trained in Journalism } \\
\hline No & $14(41 \%)$ & $7(39 \%)$ & $7(44 \%)$ \\
\hline Yes & $20(58 \%)$ & $11(61 \%)$ & $9(56 \%)$ \\
\hline \multicolumn{4}{|l|}{$\begin{array}{l}\text { Trained in environmental } \\
\text { journalism }\end{array}$} \\
\hline No & $24(71 \%)$ & $12(67 \%)$ & $13(81 \%)$ \\
\hline Yes & $9(26 \%)$ & $6(33 \%)$ & $3(19 \%)$ \\
\hline \multicolumn{4}{|c|}{$\begin{array}{l}\text { Number of years employed } \\
\text { as a journalist }\end{array}$} \\
\hline $1-2$ & $8(24 \%)$ & $3(18 \%)$ & $5(31 \%)$ \\
\hline $3-5$ & $8(24 \%)$ & $7(39 \%)$ & $1(6 \%)$ \\
\hline $6-9$ & $6(18 \%)$ & $2(11 \%)$ & $4(25 \%)$ \\
\hline $10+$ & $12(35 \%)$ & $5(28 \%)$ & $6(38 \%)$ \\
\hline \multicolumn{4}{|c|}{$\begin{array}{l}\text { Published } \geq 1 \text { environmental } \\
\text { health story } 3 \text { months prior } \\
\text { to survey date }\end{array}$} \\
\hline No & $20(59 \%)$ & $10(56 \%)$ & $10(63 \%)$ \\
\hline Yes & $14(41 \%)$ & $8(44 \%)$ & $6(38 \%)$ \\
\hline
\end{tabular}

Description: Self-reported respondent education and training histories. 
Table 3. Journalist Survey participant perception of module effectiveness by training method preference

\begin{tabular}{|c|c|c|c|}
\hline & All $(n=34)$ & Prefers Online $(\mathrm{n}=18)$ & $\begin{array}{c}\text { Prefers } \\
\text { Other }(n=16) \\
\end{array}$ \\
\hline Variables & $\mathrm{n}(\%)$ & $\mathrm{n}(\%)$ & $\mathrm{n}(\%)$ \\
\hline \multicolumn{4}{|l|}{$\begin{array}{l}\text { Pre-module topic } \\
\text { knowledge }\end{array}$} \\
\hline Very low-Low & $4(12 \%)$ & $1(6 \%)$ & $3(19 \%)$ \\
\hline Average & $21(62 \%)$ & $12(67 \%)$ & $9(56 \%)$ \\
\hline High-Very High & $9(26 \%)$ & $5(28 \%)$ & $4(25 \%)$ \\
\hline \multicolumn{4}{|l|}{$\begin{array}{l}\text { Module provided necessary } \\
\text { tools to write an article }\end{array}$} \\
\hline $\begin{array}{c}\text { Strongly } \\
\text { Disagree-Disagree }\end{array}$ & $3(9 \%)$ & $0(0 \%)$ & $3(19 \%)$ \\
\hline Neutral & $5(15 \%)$ & $3(17 \%)$ & $2(13 \%)$ \\
\hline Agree-Strongly Agree & $25(74 \%)$ & $15(83 \%)$ & $11(69 \%)$ \\
\hline \multicolumn{4}{|l|}{$\begin{array}{l}\text { Module piqued interest in } \\
\text { writing about topic }\end{array}$} \\
\hline $\begin{array}{c}\text { Strongly } \\
\text { disagree-Disagree }\end{array}$ & $5(15 \%)$ & $2(11 \%)$ & $3(19 \%)$ \\
\hline Neutral & $11(32 \%)$ & $6(33 \%)$ & $5(31 \%)$ \\
\hline Agree-Strongly Agree & $18(53 \%)$ & $10(55 \%)$ & $8(50 \%)$ \\
\hline \multicolumn{4}{|l|}{$\begin{array}{l}\text { Module improved topic } \\
\text { knowledge }\end{array}$} \\
\hline $\begin{array}{c}\text { Strongly } \\
\text { disagree-Disagree }\end{array}$ & $1(3 \%)$ & $0(0 \%)$ & $1(6 \%)$ \\
\hline Neutral & $3(9 \%)$ & $1(6 \%)$ & $3(13 \%)$ \\
\hline Agree-Strongly agree & $18(53 \%)$ & $10(55 \%)$ & $8(50 \%)$ \\
\hline \multicolumn{4}{|l|}{$\begin{array}{l}\text { Module piqued interest in } \\
\text { writing about environmental } \\
\text { topics }\end{array}$} \\
\hline No & $1(3 \%)$ & $0(0 \%)$ & $1(6 \%)$ \\
\hline Yes & $14(42 \%)$ & $9(50 \%)$ & $5(31 \%)$ \\
\hline Neutral & $19(56 \%)$ & $9(50 \%)$ & $10(63 \%)$ \\
\hline
\end{tabular}

Description: Participant evaluation of the effectiveness of the scientist-lead online environmental health journalist training module.

Table 4. Preferred method of environmental journalism instruction $(n=34)$

\begin{tabular}{lrr}
\hline \multicolumn{1}{c}{ Variables } & $\mathrm{n}$ & $\%$ \\
\hline Online module & 18 & $53 \%$ \\
Brochure & 3 & $9 \%$ \\
Audio presentation & 2 & $6 \%$ \\
Presentation & 5 & $15 \%$ \\
Other & 5 & $15 \%$ \\
\hline
\end{tabular}

Description: Self-reported preferred method of online environmental instruction.

\section{Acknowledgements}

The authors would like to thank Callie Lyons who served as the community media partner and provided valuable assistance in the undertaking of the research described here.

\section{Notes}

This study was supported by grants from the National Institute of Environmental Health Sciences (1R21ES013524-02, 5T32ES10957, R01ES016531, R03 HD059615-01, and P30-ES06096).

\section{References}

Becker, L.B., Vlad, T., Mace, N.R., Apperson, M. (2004). Midcareer Training of Journalists: Evaluating ItsImpact on Journalistic Work. James M. Cox Jr. Center for International Mass Communication Training \& Resarch Grady College of Journalism \& Mass Communication, University of Georgia. Retrieved from 
http://www.grady.uga.edu/coxcenter/Activities/Act_2003_to_2004/Materials03-04/Midcareer0304.pdf

Belch, G.E., and Belch, M.A. (2011). Advertising and Promotion: An Integrated Marketing Communications Perspective $\left(9^{\text {th }}\right.$ ed.) (pp 146-172). New York, NY. McGraw-Hill/Irwin.

Cardiff University. (2014). World's first Community Journalism MOOC. Retrieved from http://www.cardiff.ac.uk/news/articles/worlds-first-community-journalism-mooc-12334.html

George, Christy. (2009). Introduction and Current Situation. Society of Environmental Journalists. Retrieved from http://www.sej.org/about-sej/strategic-plan

Google. (2014). Online Journalism Training. Retrieved from https://www.google.com/\#q=online+journalism+training

Haynes, E.N., Beidler, C., Wittberg, R., Meloncon, L., Parin, M., Kopras, E.J., Succop, P., \& Dietrich, K.N. (2011,October). Developing a Bidirectional Academic-Community Partnership with an Appalachian-American Community for Environmental Health Research and Risk Communication. Environmental Health Perspectives, 119(10), 1364-1372. http://dx.doi.org/10.1289/ehp.1003164

Institute for Journalism \& Natural Resources. Learning Expeditions. Retreieved from http://ijnr.org/our-programs/learning-expedition s/

Israel, B.A., Schulz, A.J., Parker, E.A., \& Becker, A.B. (2001). Community-based participatory research: policy recommendations for promoting a partnership approach in health research. Edu for Health, 14(2), 182-197. http://dx.doi.org/10.1080/13576280110051055

Lin, Mu. (2014). Page views and visitors: accelerated growth in traffic. MulinBlog. Retrieved from http://www.mulinblog.com/about/

Melton, J.H., Miller, R.E., \& Kumar, A. (2014). (Un)Bundled Services: A Stakeholders' Framework for Understanding the Impact of MOOC-like, Third-Party Online Courses. Paper presented at the $47^{\text {th }}$ Hawaii International Conference on System Science. Retrieved from http://ieeexplore.ieee.org/stamp/stamp.jsp?tp=\&arnumber=6759207

Minkler, M., \& Wallerstein, N. (eds.). (2003). Community-based participatory research for health. San Francisco. Jossey-Bass.

News University. (2014). Homepage. News University. Retrieved from http://www.newsu.org/

NewsUniversity. (2014). Training. News University. Retrieved from http://www.newsu.org/search/node/environmental\%20reporting

O'Fallon, L.R., \& Dearry, A. (2002). Community-based participatory research as a tool to advance environmental health sciences. Environ Health Perspectives, 110(Suppl 2), 155-159. http://dx.doi.org/10.1289/ehp.02110s2155

Poynter Institute for Media Studies. (2013). State of Journalism Education. Poynter Institute. Retrieved from http://www.newsu.org/course_files/StateOfJournalismEducation2013.pdf

Society of Environmental Journalists. (2013). About. Retrieved from http://www.sej.org/about-sej

Society of Environmental Journalists. (2013). Education: Environmental Journalism Programs and Courses. Retrieved from http://www.sej.org/library/education-environmental-journalism-programs-and-courses

The Pew Research Center's Project for Excellence in Journalism. (2013). The State of the News Media 2013: An Annual Report on American Journalism. Pew Research Center. Retrieved from http://stateofthemedia.org/

\section{$(\mathrm{cc}) \mathbf{E Y}$}

This work is licensed under a Creative Commons Attribution 3.0 License. 